\title{
Going above and beyond for your Beliefs: the Effects of Ideological Psychological Contract Breach and Fulfillment on pro-Social Rule Breaking
}

\author{
Y. Yang $^{1}$ (D) I. Brans ${ }^{1} \cdot$ T. Vantilborgh $^{1}$ D
}

Accepted: 13 December 2021 / Published online: 23 January 2022

(c) The Author(s) 2021

\begin{abstract}
Ideological psychological contracts (PC) describe perceived obligations that relate to an organization's mission, values, and principles, and they relate closely to employees' selfconcept. The ideological currency is prevalent across various professions and organizations. In this study, we argue that employees engage in corrective behavior (i.e., pro-social rule breaking; PSRB) in response to large discrepancies between obligated and delivered ideological inducements (i.e., ideological PC breach). We measure breach obligated and delivered ideological inducements separately to examine their different effects on PSRB. Based on prior theoretical models, we examine core self-evaluation (i.e., CSE) and include perceptions of ideological PC breach and fulfillment as antecedents of PSRB, as well as the role of CSE in the relationship between perceptions of ideological PC breach and fulfillment and PSRB. Our results suggest that PSRB negatively relates to both the breach and fulfillment continua, and delivered ideological inducements relates more strongly to PSRB than obligated ideological inducements. Moreover, CSE does not moderate the relationship between ideological PC breach and fulfillment and PSRB. These results further our understanding of how ideological PCs shape employees' behavior. By examining the moderating role of CSE, we advance the PC literature by showing that ideological PC breach and fulfillment perceptions are better antecedents of PSRB than CSE.
\end{abstract}

Keywords Antecedent - Core self-evaluation · Ideological psychological contract · Prosocial rule breaking

\section{Introduction}

Many employees pursue careers for ideological values, and they are willing to make personal sacrifices for the "greater good". When the values that they hold dear are at risk, individuals go above and beyond to preserve their beliefs. During the Watergate scandal, Mark Felt believed that the FBI director at the time was obstructing the investigation by

Y. Yang

yyang@vub.be

1 Department of Work and Organizational Psychology, Vrije Universiteit Brussel, 1050 Brussel, Belgium 
leaking investigation details to the White House, so he took matters into his hands and provided critical information to the press that eventually led to the resignation of Nixon. Felt began his FBI career for patriotic beliefs, but when his ideologies are breached by his superior, he broke the organizational boundaries to strive for justice in spite of personal risks. In this study, we will explain how such behaviors can be understood through the lens of ideological psychological contract (PC) and pro-social rule breaking (PSRB).

Ideological PCs relate closely to deeply held personal values and the self-concept (Vantilborgh et al., 2014). PCs describe employees' perceptions of the mutual obligations between the employee and the employer (Rousseau, 1989), and ideological PC describes perceived obligations that relate to an organization's mission, values and principle (Thompson \& Bunderson, 2003; Vantilborgh et al., 2014). Ideological PCs are common in the sense that employees in various occupations with different functions (e.g., whitecollar and blue-collar; for- and non-profit sector) all show a considerable level of ideological currency in their PC (Krause \& Moore, 2017; Vantilborgh et al., 2014). Ideological rewards are effective inducements because contributions to a cherished cause are intrinsically rewarding (Blau, 1964). Employees perceive a breach when the organization demonstrates statements and actions that threaten the cause (Thompson \& Bunderson, 2003). The perceived breach has a profound impact on employees' self-concept, motivation and work effort (Thompson \& Bunderson, 2003; Vantilborgh et al., 2014). Employees take ideological PC breach personally and may engage in corrective behavior, such as breaking an organizational role to promote the welfare of the organization or the valued cause-called PSRB (Morrison, 2006). Both ideological PC and PSRB are primarily other-focused (Morrison, 2006). However, empirical research on how ideological PC breach and fulfillment affect PSRB is scarce (Coyle-Shapiro et al., 2019). In particular, the lack of understanding is reflected in three aspects: a) how general perceptions of breach and fulfillment of ideological PCs relate to PSRB, b) how ideological PC fulfillment and breach interact with other antecedents of PSRB, and c) whether obligated and delivered ideological inducements relate differently to PSRB.

Investigating the relationship between ideological PC breach and fulfillment and PSRB will help us to better understand the uniqueness of ideological PC. Unlike traditional PC that focuses on the transactional and relational exchange between the employer and the employee, ideological PC breach may elicit opposite reactions by the employee (Vantilborgh et al., 2014). When employees receive less ideological inducements than obligated (i.e., under-fulfillment), their self-concept is threatened (Bal \& Vink, 2011). As a result, employees redirect their effort to correct the situation rather than withdrawing their contributions (Thompson \& Bunderson, 2003). In doing so, employees may break out of the organizational boundaries that restrict them from contributing directly or indirectly to the "cause"-going above and beyond to preserve their ideologies. For example, in the public sector, employees with higher public service motivation are more likely to engage in PSRB - namely breaking organizational rules to help the citizens that they believe need and deserve help (Weißmüller et al., 2020). Morrison (2006) identified a few significant predictors of PSRB - autonomy, risk-taking propensity and co-worker behavior. However, the cognitive processes leading to the judgement that it is appropriate to break a rule remains unclear (Morrison, 2006). Therefore, understanding how ideological PC breach and fulfillment relates to PSRB will expand our understanding of ideological PC as well as shed light on the predictors of PSRB.

In addition to the predictors proposed by Morrison (2006), Vardaman et al. (2014) proposed a theoretical model where core self-evaluation (CSE), among other variables, serves as an antecedent of PSRB. CSE is considered to be a higher order personality trait that 
represents a positive self-concept (Judge et al., 1998). Similar to the PC, the CSE traits are closely related to work-related outcomes such as satisfaction and job performance (Bono \& Judge, 2003). Previous research shows that internal beliefs shape individuals' moral actions, especially when there are risks involved in these actions, such as breaking organizational rules (Shum et al., 2019). Ideological PC breach and fulfillment perceptions are employees' evaluations of the organizational context that allows them to contribute to the "cause", whereas CSE concerns the introspective evaluation of the self. Together, they address the antecedents of PSRB from both a contextual and a personal perspective. In this study, we depart from the theoretical framework by Vardaman et al. (2014) and propose as well as empirically verify a theoretical model where CSE moderates the relationship between ideological PC breach and fulfillment perceptions and PSRB. We aim to provide more understanding of how personality interacts with breach and fulfillment perceptions in leading to workplace behavioral outcomes such as PSRB.

It is important to acknowledge that various approaches exist to assess PC breach and fulfillment (Hofmans \& Vantilborgh, 2018). Many studies tend to rely on general perceptions of PC breach, in which employees are asked to mentally aggregate their evaluations (i.e., the comparison between obligated and delivered levels) of specific inducements in the PC. However, such a traditional conceptualization of PC breach and fulfillment shows several shortcomings. First, it overlooks the absolute values of obligated and delivered inducements as well as their differential effects on employees' reactions (Lambert et al., 2003). Second, it treats breach and fulfillment as two opposite ends of a single continuum, whereas research suggests that they are two independent continua (Conway \& Coyle-Shapiro, 2012). Third, it overlooks the fact that PC breach consists of both positive and negative discrepancies between obligated and delivered inducements, namely both over- and underfulfillment. Lambert et al. (2003) proposed to treat breach and fulfillment as two distinct continua: breach as a continuum ranging from under- to over-fulfillment and fulfillment as another continuum ranging from low to high absolute fulfillment. This operationalization moves away from obfuscation of how general evaluations of PC breach or fulfillment relate to outcome variables and allows us to gain a deeper and more nuanced understanding of the different effects of obligated and delivered inducements on outcome variables such as employee satisfaction (Montes \& Zweig, 2009) and PSRB (Vantilborgh et al., 2014).

This study offers three main contributions to the literature. First, by studying how ideological PC breach and fulfillment relates to PSRB, we advance our understanding of the unique outcomes of ideological PC breach and fulfillment. Second, by examining the interaction between perceptions of ideological PC breach and fulfillment and CSE, we provide empirical evidence for prior theoretical models (Morrison, 2006; Vardaman et al., 2014) as well as advance the understanding of the cognitive processes that lead to PSRB. Third, by measuring breach and fulfillment separately, we examine PC breach perceptions in a more complex way and expand our understanding of how obligated and delivered ideological inducements affect PSRB differently.

\section{Ideological Currency-A Prevalent Element in the PC}

Although economic and social-emotional currencies are traditionally considered fundamental to employees' PCs, ideological rewards should be considered effective alternative inducements as well (Thompson \& Bunderson, 2003). "Ideological currencies are credible commitments to pursue a valued cause or principle that go beyond self-interest" and are implicitly exchanged between employees and employers (Thompson \& Bunderson, 
2003, p.574). Ideological PCs involve employee beliefs that the organization is obligated to demonstrate a strong commitment and investment in a valued cause or principle, and in return, the employee is obligated to contribute to the organization's ability to pursue that cause, even if it involves personal sacrifice (Thompson \& Bunderson, 2003). In an ideological PC, the organization is expected to support the cause or the principle and provides a platform for the employee to participate in the cause, whereas the employee can initiate many behaviors that plausibly pursue their ideology (Thompson \& Bunderson, 2003). Prior research shows that ideological currency is not limited to non-profit organizations or employees in the helping profession and instead present in various types of professions and organizations (Krause \& Moore, 2017).

The defining aspect of an ideological PC is that the employee believes that the organization will provide the context in which the employee can contribute directly or indirectly to the espoused cause (Coyle-Shapiro et al., 2019). Prior research demonstrates five common characteristics of an ideologically-infused PC: (1) belief in a company's espoused cause, (2) maintaining practices, policies, and culture that advance company ideals, (3) professional pride, (4) user well-being, and (5) efforts to benefit a third party (Krause \& Moore, 2017). These elements exemplify the variety of employees' valued cause, ranging from world peace to deep-seated pride in a company's product. Employees that have an ideological element in their PCs are often willing to perform extra-role behavior such as going the extra mile to pursue their beliefs.

Once the employee believes that the organization's statements or actions may threaten the valued cause or fails to provide the context where they could contribute to the cause, a perception of ideological PC under-fulfillment emerges, even though the under-fulfillment does not directly harm the employee's personal interest (Thompson \& Bunderson, 2003). Because the organization symbolizes what the employee stands for morally, an under-fulfillment may pose a threat to the employee's beliefs and self-concept (Bal \& Vink, 2011), which triggers the employee to take the under-fulfillment "personally" and engage in corrective behavior to remedy the situation (Thompson \& Bunderson, 2003). For example, when perceiving an ideological under-fulfillment, the employee may break out of the boundaries of organizational rules to defend their self-concept and by doing so also promote the welfare of the stakeholders (Morrison, 2006).

\section{Pro-Social Rule Breaking}

As a form of corrective behavior, PSRB is the intentional violation of a formal organizational policy, regulation, or prohibition with the primary intention of promoting the welfare of the organization or its stakeholders (Morrison, 2006). Although organizational rules are important, employees often find themselves in situations where breaking the rules will advance the interest of the organization and thus feel motivated to do what he or she believes is needed to perform the job in a responsible manner (Vardaman et al., 2014). For example, employees can choose to break organizational rules to help co-workers with their tasks (Morrison, 2006; Shum et al., 2019) or to satisfy customer needs to a larger extent (Morrison, 2006). Being a form of positive work deviance, PSRB is primarily otherfocused (Morrison, 2006). Engaging in this positive rule-breaking allows employees to contribute to the ideological elements in their PC to the maximum of their ability, which as a result reinforces their self-concept (Thompson \& Bunderson, 2003).

Similar to all workplace deviant behavior, PSRB reflects an employee's conscious choice, and how an employee makes the decision to break organizational rules depends 
on a variety of individual and contextual factors (Bordia et al., 2008; Morrison, 2006). Four established models stand out in the scant literature on the antecedents of PSRB. First, Morrison (2006) proposed and tested a model where autonomy, risk-taking propensity and coworker behavior are important predictors of PSRB. More specifically, employees are more likely to break rules when they have autonomy in their role and when they have information suggesting that coworkers have rule-breaking experience. Moreover, employees that are more comfortable with risk are also more likely to engage in PSRB. Additionally, Mayer and colleagues (2007) found that employees are more likely to engage in PSRB if they have a high-quality relationship with their supervisor and if the rule they break is perceived to be unfair or unreasonable. Second, Dahling et al. (2012) further extended these findings and found that employees' conscientiousness negatively relates to PSRB whereas coworkers' PSRB and negative workplace deviance such as counterproductive work behavior relate positively to PSRB. Third, based on previous empirical evidence, Vardaman et al. (2014) proposed a conceptual model where core self-evaluation (CSE) and organizational ethical climate are included as antecedents of PSRB. Fourth, recent research on PSRB also shows that individual characteristics such as internal beliefs and motivation have a significant impact on PSRB. For example, Shum et al. (2019) found a negative relationship between moral courage and a specific form of PSRB - prosocial rule- breaking behaviors with a motive to help coworkers (i.e., PSBC) - in the hospitality industry. Weißmüller et al. (2020) found a positive relationship between public service motivation and PSRB in public-sector employees.

Based on the theoretical and empirical advancement in the literature, internal agency such as core self-evaluation and moral courage seems to play a role in predicting PSRB. Considering the mixed evidence in empirical studies, we depart from the theoretical model of Vardaman et al. (2014), by testing the relationship between CSE and PSRB. We believe that the focus on the general evaluation of the self will better explain the differences in the relationships between PSRB and other individual characteristics. Additionally, based on the commonality of ideologically driven and other-focused characteristics, we expand this theoretical framework by including ideological PC breach and fulfillment as a predictor of PSRB. Moreover, we test the interaction between CSE and perceptions of ideological PC breach and fulfillment, to address the antecedents of PSRB from both an individual and a contextual perspective.

\section{PSRB Following Ideological PC Breach and Fulfillment}

Employees' beliefs regarding an organization's commitment to and investment in a valued cause are the cornerstones of their ideological PC, whereas the organization's ideological obligations are presented in both obligated and delivered ideological inducements (Thompson \& Bunderson, 2003). Evidence shows that delivered inducements have a stronger effect on employees' attitudinal and behavioral outcomes. In particular, work related outcomes such as satisfaction, feelings of violation and employment intentions are found to be more strongly related to delivered than obligated inducements (Lambert et al., 2003; Montes \& Irving, 2008). The disproportionate effects could be explained by proximity in time and need satisfaction, namely delivered inducements contribute directly to employees' need satisfaction and are also more concurrent with satisfaction, whereas obligated inducements precede delivered inducements as well as the evaluation of PC breach and fulfillment (Lambert et al., 2003). Moreover, obligated inducements are more susceptible to employee's subjectivity and different prior experiences, whereas delivered inducements are 
less disputable and more concrete. In the context of ideological PCs, obligated ideological inducements provide the reference for employees to identify themselves with, though delivered inducements directly affect an employee's contribution or ability to contribute to the valued cause - the employee's self-concept. As a behavioral outcome of ideological PC breach, we assume that delivered ideological inducements are more strongly related to PSRB than obligated inducements. Therefore, we propose:

\section{H1: Delivered ideological inducements are more strongly related to PSRB than obli- gated inducements.}

The PC breach continuum ranges from under-fulfillment (i.e., delivered inducement falls short of obligated levels) to over-fulfillment (i.e., delivered inducement surpasses obligated levels). Ideological PC under-fulfillment triggers employees to engage in PSRB to reinforce their self-image, whereas an over-fulfillment of ideological inducements may exceed an employee's awareness of how far he or she is willing to go for his or her calling and thus be perceived as too far. According to Thompson and Bunderson (2003), employees regard the under-fulfillment of ideological inducements as threats to their self-concept and therefore take corrective actions to remedy the situation. Vantilborgh et al. (2014) showed that ideological PC under-fulfillment is related with increased rather than decreased work effort. In case of over-fulfillment, employees' attitudinal reactions depend on the nature of the inducement (Lambert et al., 2003; Montes \& Irving, 2008). Particularly, delivered inducements that satisfy employees' needs and desires will elicit positive reactions whereas those that do not will elicit negative reactions. However, ideological PC's disregard of personal interest means that an excess of inducements offers little relevance to the personal gain of the employee (Thompson \& Bunderson, 2003). In contrast, the over-fulfillment surpasses the employees' initial beliefs of the organization's commitment to the valued cause. As a result, the over-fulfilled of ideological inducements provide more resources for employees to pursue their beliefs, so that they no longer need to go the extra mile to break organizational rules. In other words, employees will be more likely to engage in PSRB in situations of under-fulfillment than in situations of over-fulfillment. Combining these arguments, we propose:

H2: The breach continuum of ideological PC relates negatively to PSRB, meaning that under-fulfillment triggers more PSRB than over-fulfillment.

PC fulfillment is a continuum that ranges from low to high absolute values, where delivered inducements equal obligated levels (Lambert et al., 2003). In the context of ideological PC fulfillment, the organization provides sufficient resources for the employee to contribute to the espoused cause. Therefore, there is no need for correcting the situation. Yet, we still propose that ideological PC fulfillment relates negatively to PSRB as the absolute level of obligated and delivered inducements matters as well. Previous research based on the expanded view shows that employees show higher satisfaction to PC fulfillment with high absolute values than that of low absolute values (Lambert et al., 2003; Montes \&Irving, 2008). Limited research on the behavioral outcome of ideological PC breach and fulfillment of volunteers shows that work effort was maximized when levels of obligated and delivered inducements were both low or both high (Vantilborgh et al., 2014). In the context of paid employees' ideological PC fulfillment, delivered inducements align with employees' expectations, resulting in an ideal situation where employees believe they are contributing to their values in an optimal manner. As the absolute value of the fulfillment 
increases, employees may feel increasingly satisfied and consequently experience a decreased need to engage in PSRB. Therefore, we propose:

H3: The fulfillment continuum of ideological PC relates negatively to PSRB, meaning that PSRB is high when obligated and delivered inducements are both low and is low when obligated and delivered inducements are both high.

\section{CSE as an Antecedent of PSRB}

"Core evaluations" - as fundamental evaluations that individuals hold about themselves, the world and others - are an integrating principle for understanding the personal bases of job-related outcomes (Bono \& Judge, 2003). CSE is a broad personality trait encompassing four underlying traits - self-esteem, locus of control, low neuroticism and generalized selfefficacy (Judge et al., 1998). Individuals with positive CSE tend to be confident that they can solve problems (high self-efficacy), that they deserve and are worthy of respect (high self-esteem), that they are responsible for and control what happens in their life (internal locus of control), and they have a great sense of optimism and experience less doubts and worries (low neuroticism) (Judge et al., 1998). These deep and bottom-line appraisals of the "self" (i.e., CSE) affect how individuals evaluate specific situations such as one's work (Bono \& Judge, 2003). An employee with high self-esteem will more likely form a PC where the mutual obligations are well defined, and they are more likely to monitor the exchange relationship more vigilantly in order to protect their self-concept (Shih \& Chuang, 2013).

CSE is a significant predictor for work-related outcomes such as job satisfaction and performance (Judge et al., 1998). Interestingly, intrinsic job characteristics such as having a rewarding job and motivation are found to mediate these relationships. In an ideological PC, the cause that employees pursue symbolizes what the employee stands for and provides intrinsic rewards. Therefore, employees with high CSE may be more likely to engage in situations where their self-concept can be reinforced, for example by initiating PSRB. Vardaman et al. (2014) theorized the anteceding role of CSE for PSRB. In specific, selfesteem, self-efficacy, an internal locus of control, and low neuroticism are positively related with PSRB. In this study, we treat CSE as one construct-an integrated self-concept-and assume that a positive self-concept will be positively related to PSRB.

\section{H4: CSE is positively related to PSRB.}

\section{CSE as a Moderator in the Relationship between Ideological PC Evaluation and PSRB}

A positive self-concept is the key element linking ideological PC, CSE and PSRB (Judge et al., 1998; Morrison, 2006; Thompson \& Bunderson, 2003). As previously argued, CSE has been theorized to be an antecedent of PSRB (Vardaman et al., 2014) and to be positively related to PSRB. Likewise, we argued that ideological PC breach and fulfillment are antecedents of PSRB. However, the relationship between ideological PC breach and fulfillment and PSRB is more complex when we take into consideration the absolute values of obligated and delivered inducements. For example, a company may claim to care a great deal about their environmental impact, yet most meals in the cafeteria are packed in disposable plastic packages. In this situation, the employee who is concerned about climate change may perceive an under-fulfillment of the ideological currency. On the other hand, a 
company may promise to donate $5 \%$ of its profits to a charity at the end of the year. When the donation at the yearend is higher than this amount, the employees may perceive it as an over-fulfillment or over-obligation. Simply put, both ideological PC under- and overfulfillment are perceived as a threat to an individual's self-concept, whereas a fulfillment is perceived as a reinforcement of the self-concept. An important next question we need to ask is how CSE interacts with ideological PC evaluation in predicting PSRB.

The interaction between CSE and perceptions of ideological PC breach and fulfillment could offer more insight on the behavioral outcomes of ideological PC evaluations as well as the antecedents of PRSB. Based on the reasoning for hypotheses two and three, we assume that in the context of ideological PCs, CSE and perceptions of PC breach and fulfillment are important antecedents of employees' corrective behavior (i.e., PSRB). In particular, we assume that as absolute fulfillment increases, employees engage in less PSRB. However, employees with different levels of self-evaluation may show varying degrees of decrease. More specifically, in case of a PC breach, employees with low CSE feel less in control and may as a result believe that engaging in PSRB is not a viable action to react to the discrepancy between obligated and delivered ideological inducements, whereas employees with high CSE feel capable and in control and thus initiate more PSRB to correct the situation (Judge \& Bono, 2001). As a result, as we move along the breach continuum from under- to over-fulfillment, employees with high CSE will engage in more PSRB than those with low CSE. On the other hand, as the absolute value of fulfillment increases, employees engage in less PSRB. However, employees with low CSE attribute the high level of obligated and delivered ideological inducements to extrinsic forces and may still feel the need to engage in PSRB to live up to the standards of the organization, whereas those with high CSE initiate less PSRB because they feel in control of the situation and attribute the high level of fulfillment to their positive evaluations of the self. In sum, we propose:

H5a: CSE moderates the effects of breach on PSRB, with stronger effects when CSE is high.

H5b: CSE moderates the effects of fulfillment on PSRB, with weaker effects when CSE is high.

\section{Methods}

\section{Sample}

Based on the prevalence of the ideological currency in employees' PCs (Krause \& Moore, 2017), we recruited 389 employees across various organizations in Flanders (Belgium) to participate in the study. The data collection was conducted by the second author with a convenience sampling technique - a time and cost effective way to collect data (Etikan et al., 2016). The second author used her social and professional networks to reach potential participants in various organizations. The potential participants are added to a Qualtrics panel, through which a short survey with the research goals was sent to the participants. By providing their email addresses, the participants gave their informed consent. A total of 341 participants responded to Time 1 (T1) survey and had a completion rate of $79 \%$, and 296 participants from the same panel responded to Time 2 (T2) survey and had a completion rate of $88 \%$. In total, 238 participants completed both surveys. The average age of the 
participants was 35 years old $\left(S D=10, \operatorname{Min}_{\text {age }}=21\right.$, Max $\left._{\text {age }}=65\right)$. The participants had an average tenure of 4.22 years in their current organization $\left(S D=5.50\right.$, Min ${ }_{\text {tenure }}<1$, Max age $=36$ ). $64 \%$ of the participants were male, and no participant reported gender other than male and female. The participants worked in various sectors, with a majority in ICT (64\%) and consulting (11.4\%). Regarding the educational background of the participants, $48.7 \%$ held a bachelor's degree, $35.3 \%$ a master's degree, and $12.3 \%$ a higher secondary school degree. The majority of the participants worked full-time (92\%).

\section{Procedure}

We adopted a two-wave prospective design and administered self-report surveys via Qualtrics at two time points, with a time lag of two weeks between measurement moments (Taylor, Kluemper, \& Sauley, 2009). Before the first measurement moment, an email with an introduction to the survey and an informed consent was sent to the participants. By signing the informed consent, participants could start the T1 survey, which measured obligated ideological inducements and core self-evaluation. Two weeks later, the same participants received a second email containing the same introduction to the survey and an individual link to the T2 survey, which collected data of delivered ideological inducements and PSRB. One and a half week after sending each survey, a reminder email was sent to the participants if they had not yet completed the survey.

\section{Measures}

The data of this study was collected together with another study that examined organizational ethical climate as an antecedent of PSRB, but data on ethical climate is not used in this study. A full list of measures can be consulted in Appendix 1. In both T1 and T2 surveys, the series of questions were randomized.

Demographic Variables In T1 survey, we collected information of participants' gender, age (in years), level of education, job sector, employment status (full-time or part-time), and tenure in the current organization.

Obligated and Delivered Ideological Inducements The extent to which ideological inducements are obligated and delivered were measured with Bingham's (2005) obligated and delivered ideological contract scale (ICS obligated and ICS delivered). The scales contain questions regarding the obligated and delivered levels of nine ideological inducements (See Appendix 2). The participants are instructed to indicate on a five-point Likert scale how much they agreed with the statements $(1=$ Strongly disagree, $5=$ Strongly agree $)$. The instruction for obligated inducements is "I feel my company is obligated to", whereas the instruction for delivered inducements is "I think the organization succeeds effectively in". Cronbach's $\alpha$ of these scales achieved an acceptable level of reliability $\left(\alpha_{\text {obligated }}=.85\right.$, $\left.\alpha_{\text {delivered }}=.90\right)$.

CSE We used the CSE scale developed by Judge et al. (2003) to measure participants' CSE (see Appendix 3). We asked the participants to rate each one of the 12 items on a five-point Likert scale $(1=$ Strongly disagree, $5=$ Strongly agree). Items that imply negative CSE are reverse scored (e.g., "sometimes I feel depressed"). Cronbach's $\alpha$ of the scale achieved an acceptable level of reliability $\left(\alpha_{\mathrm{CSE}}=.83\right)$. 
PSRB We adopted the general PSRB scale by Dahling et al. (2012) to measure participants' positive rule-breaking behavior (See Appendix 4). Because the participants were Dutch-speaking and no Dutch version of this scale was available, we used the back-translation technique to obtain a Dutch version (Douglas \& Craig, 2007). The participants were instructed to rate each of the 13 items on a five-point Likert scale $(1=$ Strongly disagree, $5=$ Strongly agree). Cronbach's $\alpha$ of the scale achieved an acceptable level of reliability $\left(\alpha_{\mathrm{PSRB}}=.93\right)$.

\section{Analyses}

We use polynomial regression analysis and response surface methodology to avoid issues that are inherent to traditional approaches of PC breach and fulfillment, such as using difference scores (i.e., algebraic or squared difference scores between obligated and delivered inducements; Vantilborgh et al., 2014). As Edwards (1994) pointed out, first, difference scores conceal the true contributions of obligated and delivered inducements; second, difference scores constrain the estimates of obligated inducements and delivered inducements to be equal in size but opposite in sign; third, difference score methods reduce the inherently three-dimensional relationship of obligated and delivered inducements with outcomes into a two-dimensional relationship (Lambert et al., 2003). As an alternative, Edwards and Parry (1993) suggested using polynomial regression analysis and response surface methods. Following the recommendations of Edwards and Parry (2003), we estimated increasingly complex polynomial models and selected the most parsimonious model that explains the most variance in the dependent variable. The estimates from the selected model are then used to construct a response surface. This approach is illustrated in the following set of equations.

Eq. 1 denotes the first-order model, where PSRB (Z) is the dependent variable, and obligated $(\mathrm{X})$ and delivered $(\mathrm{Y})$ inducements are added as independent variables. In Eq. 2, we introduced the interaction between obligated and delivered inducements as well as their second-order terms to capture nonlinear effects, since it is often not realistic to assume linear relationships (Edwards, 2002; Vantilborgh et al., 2014). Before conducting the regression analysis, we scale centered each pair of obligated and delivered inducements (Edwards, 2002). Furthermore, we mean centered CSE. The scaling facilitated interpretation and removed undesired collinearity (Lambert et al., 2003; Vantilborgh et al., 2014).

To assess whether CSE moderates the relationship between breach and fulfillment perceptions of ideological PC and PSRB, we introduced a moderator to the model. Equation 3 shows the second-order model with obligated inducements $(\mathrm{X})$, delivered inducements $(\mathrm{Y})$ as independent variables, PSRB (Z) as the dependent variable, and CSE (M) as the moderator. Equation 4 shows the interaction term between the moderator and the first-order as well as secondorder independent variables. Equation 4 can be rewritten to Eq. 5 to simplify the coefficients for each independent variable.

$$
\begin{gathered}
\mathrm{Z}=b_{0}+b_{1} \mathrm{X}+b_{2} \mathrm{Y}+e \\
\mathrm{Z}=b_{0}+b_{1} \mathrm{X}+b_{2} \mathrm{Y}+b_{3} \mathrm{X}^{2}+b_{4} \mathrm{XY}+b_{5} \mathrm{Y}^{2}+e \\
\mathrm{Z}=b_{0}+b_{1} \mathrm{X}+b_{2} \mathrm{Y}+\mathrm{b}_{3} \mathrm{M}+b_{4} \mathrm{X}^{2}+b_{5} \mathrm{XY}+b_{6} \mathrm{Y}^{2}+e \\
\mathrm{Z}=b_{0}+b_{1} \mathrm{X}+b_{2} \mathrm{Y}+b_{3} \mathrm{X}^{2}+b_{4} \mathrm{XY}+b_{5} \mathrm{Y}^{2}+\mathrm{b}_{6} \mathrm{M}+b_{7} \mathrm{XM}+b_{8} \mathrm{YM}+b_{9} \mathrm{X}^{2} \mathrm{M}+b_{10} \mathrm{XYM}+b_{11} \mathrm{Y}^{2} \mathrm{M}+e
\end{gathered}
$$




$$
\mathrm{Z}=\left(b_{0}+b_{6} \mathrm{M}\right)+\left(b_{1}+b_{7} \mathrm{M}\right) \mathrm{X}+\left(b_{2}+b_{8} \mathrm{M}\right) \mathrm{Y}+\left(b_{3}+b_{9} \mathrm{M}\right) \mathrm{X}^{2}+\left(b_{4}+b_{10} \mathrm{M}\right) \mathrm{XY}+\left(b_{5}+b_{11} \mathrm{M}\right) \mathrm{Y}^{2+} e
$$

To assist interpretation of the regression coefficients, we plotted their response surface of the combined effects of obligated and delivered inducements on employees' PSRB (Edwards \& Parry, 1993). In this surface, two lines are essential in testing the hypotheses: the fulfillment and breach lines (see Fig. 1). The estimates along the breach line informs us how PSRB changes as we move from under- to over-fulfillment, whereas the fulfillment line provides information of how PSRB changes as the absolute value of fulfillment increases from low to high. We calculated the slopes and curvatures by linearly combining the regressions coefficients (Edwards, 2002).

\section{Results}

Given that $70 \%$ of the initial panel of participants completed both surveys, we performed a logistic regression to test whether the demographic variables and CSE scores predicted any systematic drop-out. Results suggest that only employment status (full-time or part-time) significantly predicted whether the participants completed both surveys. In particular, fulltime employees are $35.7 \%$ more likely to complete both surveys than part-time employees $(p=.035)$. CSE did not play a role in predicting completion rate.

We performed confirmatory factor analyses (CFA) to test the factor structure of the measures that we used for obligated and delivered ideological inducements, CSE and

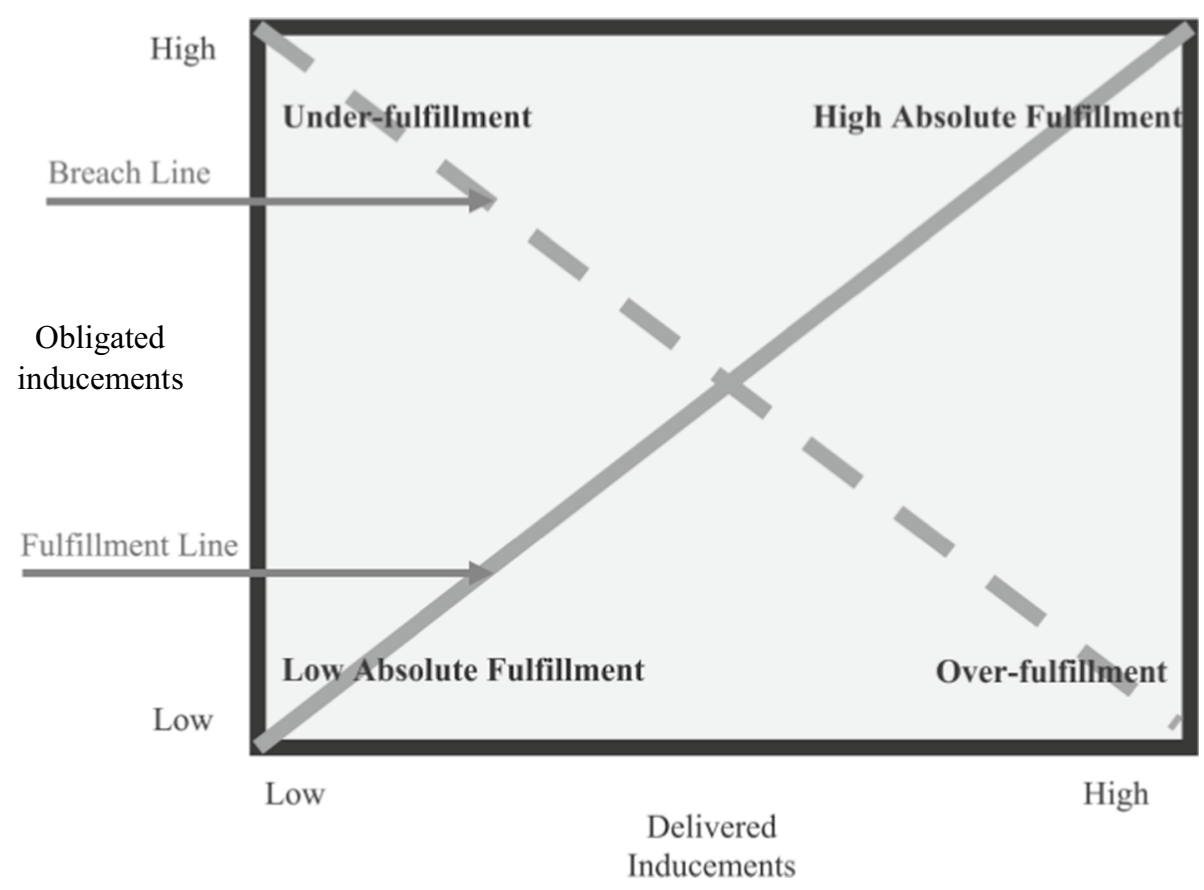

Fig. 1 Illustrative aid for interpreting PC breach and fulfillment lines in response surfaces (Montes \& Irving, 2008) 
Table 1 Results from confirmatory factor analyses

\begin{tabular}{llllllll}
\hline Measures & \multicolumn{7}{l}{ Model fit indices } \\
\cline { 2 - 8 } & $X^{2}$ & $d f$ & $X^{2} / d f$ & $R M S E A$ & $C F I$ & $T L I$ & $S R M R$ \\
\hline Obligated & $68.45 * * *$ & 27 & 2.54 & .073 & .946 & .927 & .039 \\
Delivered & $64.20^{* * *}$ & 27 & 2.38 & .074 & .967 & .956 & .032 \\
CSE & $130.78^{* * *}$ & 54 & 2.42 & .070 & .902 & .880 & .053 \\
PSRB & $280.13^{* * *}$ & 65 & 4.31 & .116 & .889 & .866 & .055 \\
\hline
\end{tabular}

Notes: $* * * p<.001$. Recommended values for model fit indicators: good fit: $X^{2} / d f \leq 2 ;$ RMSEA $\leq .05 ;$ SRMR $\leq .05 ; .97 \leq \mathrm{CFI} \leq 1.00$; $.97 \leq \mathrm{TLI} \leq 1.00$; acceptable fit: $2 \leq X^{2} / d f \leq 3 ; .05<$ RMSEA $\leq .08$; $05<\mathrm{SRMR} \leq .10 ; .95 \leq \mathrm{CFI} \leq .97 ; .95 \leq \mathrm{TLI} \leq .97$ (Schermelleh-Engel et al., 2003)

Table 2 Descriptive statistics, reliability and correlations

\begin{tabular}{llllllll}
\hline Measures & Mean & SD & Cronbach's $\alpha$ & Obligated & Delivered & CSE & PSRB \\
\hline Obligated & 4.02 & .46 & .85 & 1 & & & \\
Delivered & 3.78 & .62 & .90 & .047 & 1 & & \\
CSE & 3.67 & .55 & .83 & .054 & $.234^{* *}$ & 1 & \\
PSRB & 2.93 & .73 & .93 & .049 & $-.241^{* *}$ & -.114 & 1 \\
\hline
\end{tabular}

Notes: ** $p<.01$. Recommended values for Cronbach's alpha: excellent: $\alpha \geq .90$; good: $.70 \leq \alpha \leq .90$; acceptable: $.60 \leq \alpha \leq .70$; unacceptable: $\alpha \leq .50$ (Tavakol \& Dennick, 2011)

PSRB. The results (see Table 1) suggest that all the fit indices were generally acceptable. Moreover, we examined the correlations between the measures (See Table 2). Only delivered ideological inducements are significantly correlated with CSE and PSRB, whereas obligated ideological inducements do not significantly relate to CSE or PSRB. In particular, delivered ideological inducements relate positively to $\operatorname{CSE}(r=.234, p<.001)$ and negatively to PSRB $(r=-.241, p<.001)$. Hypothesis 1 is aimed at comparing the strength of the relationships between obligated and delivered inducements and PSRB. We performed a fisher $z$-test to compare the two correlations, and the results $(z=-2.3, p=.02)$ suggest that PSRB relates more strongly to delivered than obligated inducements. Hypothesis 4 aims to examine whether there is a positive relationship between CSE and PSRB. However, the correlational results do not provide evidence to support this relationship.

We applied a stepwise procedure to test the other hypotheses. In Model 1 (Eq. 1) we regressed PSRB on first-order independent variables (obligated and delivered ideological inducements). In Model 2 (Eq. 2) we regressed PSRB on first-order as well as second-order independent variables. We compare the change in $R^{2}$ to determine which model explains the majority of the variance in the most efficient way. The results (see Table 3 ) suggest that both Model $1(F(2,237)=8.43, p<.001)$ and Model $2(F(5,234)=3.76, p=.003)$ explain a significant amount of variance in PSRB. Although Model 2 explains an additional 7\% variance in PSRB, it did not significantly improve the first-order model $(p=.58)$. Hence, we used the regression coefficients of the first-order model to plot the response surface (Fig. 2). The selected first-order model provides additional support for Hypothesis 1 -delivered inducements relates more strongly to PSRB than obligated inducements $\left(\beta_{\text {delivered }}=-.30^{* * *}, \beta_{\text {obligated }}=.10\right)$. 
Table 3 Correlation between obligated, delivered inducements, CSE, PSRB, age and tenure

\begin{tabular}{llllll}
\hline & Age & Tenure & Obl & CSE & Del \\
\hline Age & & & & & \\
Tenure & $.494^{* *}$ & & & & \\
Obl & $-0,068$ & $-0,066$ & & & \\
CSE & $.205^{* *}$ & 0,093 & 0,067 & & \\
Del & $-0,030$ & $-.164^{*}$ & 0,043 & $.231^{* *}$ & \\
PSRB & 0,060 & 0,020 & 0,057 & $-0,113$ & $-.248^{* * *}$ \\
\hline
\end{tabular}

Notes: $* * p<.01, * p<.05$

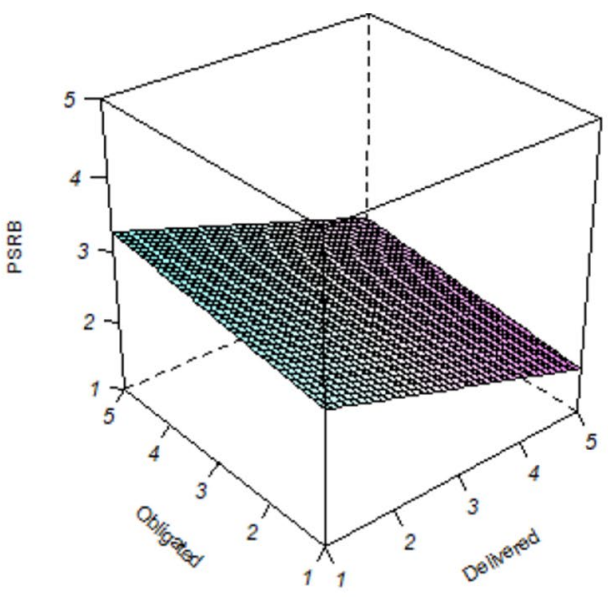

Breach continuum

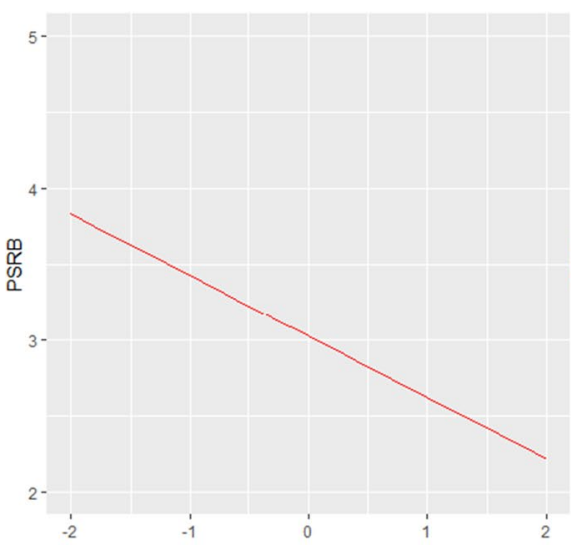

Fulfillment continuum

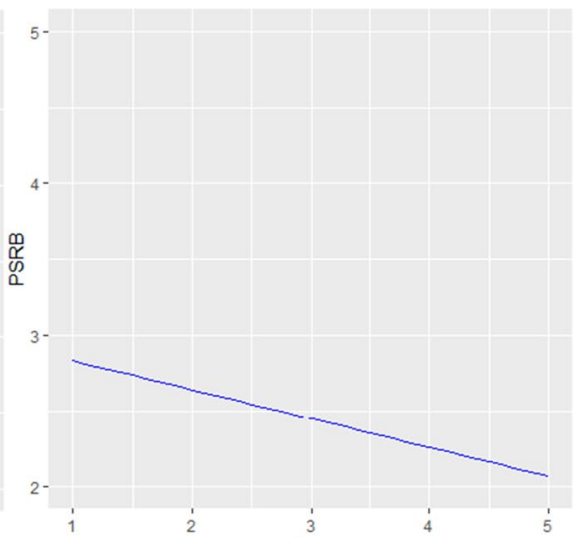

Fig. 2 Response surface with associated lines of breach and fulfillment of the polynomial regression for ideological inducements explaining PSRB

Based on the response surface, we plotted the breach line and the fulfillment line. The breach line goes from delivered-low obligated-high to delivered-high obligated-lowin other words, from under-fulfillment to over-fulfillment. The slope of the breach line 
can be calculated with $b_{2}-b_{1}$ (Eq. 1), resulting in a significant negative slope $(\beta=-.40$, $p<.001)$. This means that as we move from under- to over-fulfillment, PSRB decreases. This provides support to Hypothesis 2. The slope of the fulfillment line can be calculated with $b_{2}+b_{1}$ (Eq. 1), resulting a significant negative slope $(\beta=-.20, p<.001)$. As we move along the fulfillment line from low to high absolute values, we see a decreasing line in PSRB, supporting Hypothesis 3.

In Model 3 (Eq. 3) we introduced the moderator CSE into the model and regressed PSRB on the main effects of the first-order independent variables, the moderator as well as interaction terms between the independent variables and the moderator (see Table 3). The main-effect model explains significantly explains $7 \%$ of variance in PSRB $(F$ (3, $233)=5.87, p<.001)$, whereas the interaction model explains $2 \%$ more variance in PSRB $(F(5,231)=4.38, p<.001)$. However, this difference is not significant $(p=.13)$, meaning that there is no significant interaction between ideological PC breach and fulfillment and CSE, suggesting that Hypotheses 5a and 5b are not supported. Therefore, we selected the simpler model with the main effects of the independent variables as well as the moderator. As our results suggest that there is no significant interaction between CSE and PC breach and fulfillment perceptions, the effect of PC breach and fulfillment on PSRB is not significantly moderated by CSE. Although CSE has a negative main effect on PSRB, this effect is not significant. The main effects of delivered as well as obligated inducements are shown in Fig. 2, and the lines of interest are also reflected in Fig. 2. In particular, along the breach continuum, individuals engaged in more PSRB in situations of under-fulfillment than in situations of over-fulfillment, and along the fulfillment continuum, individuals engage in less PSRB when the absolute value of the fulfillment is high than when the absolute value of fulfillment is low (Table 4).

\section{Discussion}

The primary goal of this study is to expand the research on the behavioral outcome of ideological PC breach and fulfillment-specifically PSRB-and how CSE interacts with breach and fulfillment perceptions in the cognitive process leading to PSRB. We positioned the theoretical model within Vardaman et al.' (2014) framework and set out to verify the

Table 4 Polynomial regression analyses with PSRB as dependent variable

\begin{tabular}{lclll}
\hline & Step 1 & Step 2 & Step 3 & Step 4 \\
\hline Intercept & $3.02 * * *$ & $3.25 * * *$ & $3.01 * * *$ & $3.02 * * *$ \\
Obligated (X) & .10 & -.20 & .11 & .12 \\
Delivered (Y) & $-.30^{* * * *}$ & $-.57 * *$ & -.28 & $-.29 * * *$ \\
Obligated squared (X $\left.{ }^{2}\right)$ & & .06 & & \\
Obligated x Delivered (XY) & & .19 & & \\
Delivered squared (Y) & & .06 & & \\
CSE (M) & & & -.09 & .24 \\
Obligated x CSE (XM) & & & & -.16 \\
Delivered x CSE (YM) & & & & -.22. \\
$\mathrm{R}^{2}$ & $.067 * * *$ & $.074 * *$ & $.071 * * * .087 * * *$ \\
$\mathrm{R}^{2}$ changed & & .007 & & .016 \\
\hline
\end{tabular}

Notes: $* * * p<.001 . * * p<.01 . * p<.05 . \mathrm{p}<.1$ 
relation between CSE and PSRB, extending previous research on the predictors of PSRB. Moreover, we aimed to bridge the research on ideological PC and PSRB. Therefore, PSRB was theorized to be a form of corrective behavior with ideological PC breach and fulfillment perceptions as antecedents of PSRB. We integrated the expanded view of the PC and treated obligated and delivered ideological inducements as two distinct continua. As we predicted, both the breach and fulfillment continua of ideological PCs relate negatively to PSRB. Delivered ideological inducements relate more strongly to PSRB than obligated inducements. Contrary to our prediction as well as the theoretical framework of Vardaman et al. (2014), CSE does not moderate the relationship between ideological PC breach and fulfillment perceptions and PSRB, nor is its main effect on PSRB significant.

\section{Theoretical Implications}

Our first and foremost finding regarding the behavioral outcome of ideological PC breach and fulfillment is that corrective behavior is not exclusive to PC breach. Traditionally, PC under-fulfillment is found to have detrimental effects on employees' well-being and workrelated behavior, whereas PC fulfillment is theorized to be related to positive attitudinal and behavioral outcomes (Zhao et al., 2007). However, there is little evidence supporting the positive relationship between PC fulfillment and positive work behavior in general. Comparing ideological and relational PCs, Vantilborgh et al. (2014) found that there is a curvilinear relationship between work effort and ideological PC fulfillment-namely, as absolute fulfillment increased, work effort first decreased and then increased. We applied the expanded view approach of the PC (Lambert et al., 2003) to ideological PCs and PSRB. Our results suggest that employees engage in less PSRB as the absolute level of their ideological PC fulfillment increases and when they receive an over-fulfillment of ideological inducements.

This finding offers three main contributions to the literature. First, we provide more empirical support for the expanded view-namely, ideological PC under- and over-fulfillment as well as the absolute levels of fulfillment have distinct relationships with PSRB. This finding encourages future research to treat PC breach and fulfillment as distinct continua. Second, PSRB, as a form of positive work deviance, is intended to benefit the organization or its stakeholders when the organizational context allows for it (Morrison, 2006). Under-fulfillment or low absolute values of ideological PC implies that the organization does not uphold an ideological mission or at least does not value ideological currency in their exchange with employees and other stakeholders. Therefore, employees engage in PSRB to compensate for the lack of contextual support from the organization. Fulfillment of ideological inducements, on the other hand, implies an alignment between the employee's and employer's vision in the ideological aspect and provides sufficient resources for the employee to pursue their valued cause, thus reducing the need for the employee to break organizational rules to achieve their goal. Third, an over-fulfillment of ideological inducements is the other side of the discrepancy coin. An over-fulfillment of one aspect may comprise other aspects that are also important to the employee's espoused values. For example, an organization may be devoted to enhancing customers' experiences, whereas some employees may not receive enough resources to perform their job the way they would like to. In this case, employees might engage in PSRB to help their coworkers, in an effort to rectify the situation.

Second, our results suggest that delivered ideological inducements are more strongly associated with PSRB than obligated inducements. We extended previous research 
disentangling the effects of obligated and delivered PC inducements (Lambert et al., 2003; Montes \& Irving, 2008) to another important PC element-ideological inducements. Although obligated ideological inducements provide employees with an anchor point to identify their own beliefs with the organization's values, delivered inducements offer concrete means for employees to examine how much the organization supports or violates their valued beliefs. Hence, our results support the expanded approach that distinguishes the effects of obligated and delivered inducements in a broader PC context.

Third, in contrast to our prediction and the theoretical model of Vardaman et al. (2014), we did not find a significant association between CSE and PRSB. There could be two explanations. First, people with high CSE by definition hold positive assumptions about themselves and their world and are more likely to experience high job and life satisfaction (Judge \& Bono, 2001). In other words, they may feel content with the context that the employer provides for them to pursue their values and believe that their jobs are highly rewarding. Shum et al. (2019) found that employees with higher moral courage are less likely to engage in rule-breaking behavior to help their colleagues, suggesting that individuals with higher levels of internal agency are more willing to bear the risks associated with their moral behavior such as not being able to form a friendly relationship with coworkers. Therefore, employees with high CSE experience little need to break organizational rules. Second, we regard CSE as an umbrella construct that encompasses four traitsself-esteem, general self-efficacy, locus of control, and neuroticism (Judge et al., 1998). Although these traits are closely related (Bono \& Judge, 2003), they may relate differently to PSRB. Vardaman et al. (2014) proposed that self-esteem, self-efficacy, and internal locus of control are positively associated with PSRB, whereas neuroticism and external locus of control associate negatively to PSRB. Moreover, Morrison (2006) proposed that PSRB closely relates to empathy and self-esteem. This study is a first attempt to provide empirical evidence for the relationship between personality and PSRB in the context of the $\mathrm{PC}$, inviting more empirical research on the relationships between the various individual traits and PSRB.

Finally, contrary to our prediction, CSE does not moderate the relationships between ideological PC breach and fulfillment and PSRB. Vardaman et al. (2014) theorized CSE as an antecedent of PSRB, but our results of Hypothesis 4 and 5 challenge this proposition. The results suggest that the delivered ideological inducements employees receive from the organization can more strongly predict how much employees engage in PSRB, compared to CSE. A possible interpretation could be that ideological PC breach and fulfillment have more direct consequences on the context that an organization provides for employees to pursue their valued cause. PSRB, as a selfless behavior, is performed by employees for the interests of the organization or its stakeholders (Morrison, 2006), so that employees can uphold their values by doing their job. As a result, the organizational context relates more strongly to employees' deviant behavior.

\section{Practical Implications}

First, organizations need to avoid under-fulfilling ideological inducements if they want to prevent occurrence of PSRB. An under-fulfillment of ideological PC indicates the organization's failure to support the employee to achieve their ideological goals, and this may be perceived as very negative by employees. News coverage worldwide has shown that during the Corona pandemic, health care professionals across the world have been going the extra mile to save as many patients as possible, sometimes even putting their own safety 
at danger (Gupta et al., 2020). Second, organizations should be aware that delivered ideological inducements are very important to employees. As the absolute values of ideological PC fulfillment increases, employees engage in less PSRB. This implies that organizations that want to avoid PSRB should keep employees' ideological PCs fulfilled and preferably to higher levels. Third, PSRB, as a positive work deviant behavior, serves to benefit the organization or its stakeholders. Decision-makers need to be mindful of the nature of PSRB before deciding whether PSRB needs to be avoided. It might be helpful for organizations to allow PSRB in certain situations. For example, a drug store manager breaks rules and delivers items to elderly customers, because it's hard for them to get out, and not a big deal for him/her to do it on his/her way home. The customer will most likely feel grateful to the manager or the drug store and experience an increased satisfaction, which might also increase the reputation of the store (Morrison, 2006). Moreover, helping a coworker who needs to leave in a hurry to pick up their sick child to clock in helps to create a friendly working relationship in the organisation where employees may feel more supported by their coworkers and the organisation (Shum et al., 2019).

\section{Limitations}

In this study, we collected data at two time points to prevent common method bias (Podsakoff et al., 2003; Vantilborgh et al., 2014). It allows us to capture the temporal precedence of the key variables. However, the time lag may have certain disadvantages, such as selection bias-namely, it is possible that people who experienced severe PC breach at T1 did not participate in T2 (Vantilborgh et al., 2014). Our results suggest that full-time employees tend to stay in the study, compared to part-time employees. It is also possible that part-time employees have fewer opportunities to experience PC breach and fulfillment as well as to engage in corrective behavior, compared to their full-time employed counterparts, though previous research has shown that part-time employees respond in similar ways as full-time employees to PC breach and fulfillment, in terms of attitudinal and behavioral outcomes (Conway \& Briner, 2002a). Second, while scholars are increasingly calling for treating the $\mathrm{PC}$ as a dynamic phenomenon, our study does not focus on the temporal changes in the key constructs and rather treats them as static. Recent PC research offers empirical evidence that employees experience breach on a daily (Conway \& Briner, 2002b), weekly (Vantilborgh et al., 2016) or monthly (Robinson \& Rousseau, 1994) basis. Therefore, a dynamic approach that captures the temporal fluctuations of employees' breach perceptions as well as self-evaluations may offer a clearer picture of how ideological PC breach and fulfillment perceptions interact with CSE to elicit PSRB.

\section{Recommendations for Future Research}

First, to better capture the dynamic nature of the PC, future research could opt for more measurement points and link the temporal changes of PC breach and fulfillment perceptions with those of CSE as well as of PSRB. It is possible that repeated breach events have an effect on employees' self-evaluations and organizational commitment (Cassar \& Briner, 2011; de Jong et al., 2017), which in turn affects employees' work behavior (Griep \& Vantilborgh, 2018). Second, although ideological currency is prominent in various PCs, employees throughout sectors and occupations may experience ideology differently (Bal \& Vink, 2011). Therefore, we encourage future research to replicate our findings with a more 
homogeneous sample that may share similar understanding of the ideological currency in their PC.

\section{Conclusions}

We positioned the theoretical model of Vardaman et al. (2014) regarding the relation between CSE and PSRB in the PC context, empirically examined this model and found that perceptions of PC breach and fulfillment are better predictors of PSRB than CSE. Furthermore, we extended the expanded view of the PC (Lambert et al., 2003) and provided evidence that the fulfillment as well as the breach continua associate negatively to PSRB, providing more insight in the unique behavioral outcomes of ideological PC. We also extended previous findings on the differential effects of obligated and delivered inducements to ideological PCs and found that delivered ideological inducements relate more strongly to PSRB than do obligated inducements, providing more nuanced understanding of how delivered and obligated inducements bear different weight on outcomes. We examined the interaction between two possible antecedents of PSRB-namely, CSE and perceptions of ideological PC breach and fulfillment - and showed that CSE does not moderate the relationship between ideological PC breach and fulfillment and its corrective behavior.

\section{Appendix 1}

Table 5 .

Table 5 Variables measured in the data collection

\begin{tabular}{lll}
\hline & Variable & $\begin{array}{l}\text { Whether } \\
\text { used in this } \\
\text { study }\end{array}$ \\
\hline 1. & Obligated ideological inducements & Yes \\
2. & Delivered ideological inducements & Yes \\
3. & Core self-evaluation & Yes \\
4. & Pro-social rule breaking & Yes \\
5. & Demographic variables & Yes \\
6. & Organizational ethical climate & No \\
\hline
\end{tabular}




\section{Appendix 2}

Table 6.

Table 6 Ideological inducements

1. Contribute to the stated cause

2. Commit resources toward advancing the stated cause

3. Stand behind our corporate ideology, even if it requires a financial sacrifice

4. Provide opportunities for involvement in our cause

5. Encourage employee involvement in the cause

6. Act as a public advocate of the espoused cause

7. Be dedicated to my company's mission

8. Maintain company culture that promotes our corporate principles

9. Create internal practices and policies that advance my company's ideals

\section{Appendix 3}

Table 7 .

Table 7 Items for core self-evaluation

1. I am confident I get the success I deserve in life.

2. Sometimes I feel depressed. (r)

3. When I try, I generally succeed.

4. Sometimes when I fail I feel worthless. (r)

5. I complete tasks successfully.

6. Sometimes, I do not feel in control of my work. (r)

7. Overall, I am satisfied with myself.

8. I am filled with doubts about my competence. (r)

9. I determine what will happen in my life.

10. I do not feel in control of my success in my career. (r)

11. I am capable of coping with most of my problems.

12. There are times when things look pretty bleak and hopeless to me. (r)

$(\mathrm{r})=$ reverse-scored 


\section{Appendix 4}

Table 8.

Table 8 Items for pro-social rule breaking

1. I break organizational rules tor policies to do my job more efficiently.

2. I violate organizational policies to save the company time and money.

3. I ignore organizational rules to "cut the red tape" and be a more effective worker.

4. When organizational rules interfere with my job duties, I break those rules.

5. I disobey company regulations that result in inefficiency for the organization.

6. I break organizational rules if my coworkers need help with their duties.

7. When another employee needs my help, I disobey organizational policies to help him/her.

8. I assist other employees with their work by breaking organizational rules.

9. I help out other employees, even if it means disregarding organizational policies.

10. I break rules that stand in the way of good customer service

11. I give good service to clients or customers by ignoring organizational policies that interfere with my job.

12. I break organizational rules to provide better customer service.

13. I bend organizational rules so that I can best assist customers.

\section{Appendix 5}

Table 9.

Table 9 Frequency table of socio-demographic characteristics of the sample

\begin{tabular}{ll}
\hline Socio-demo variable & Percentage \\
\hline Gender & \\
Male & $63.7 \%$ \\
Female & $36.3 \%$ \\
Age & \\
$18-24$ & $16.0 \%$ \\
$25-34$ & $40.9 \%$ \\
$35-44$ & $21.9 \%$ \\
$45-54$ & $16.0 \%$ \\
$55+$ & $5.1 \%$ \\
Education & \\
Less than primary, primary and lower secondary & $1.7 \%$ \\
Higher secondary & $11.0 \%$ \\
Bachelor and master & $84.4 \%$ \\
Others & $3.0 \%$ \\
Sector & \\
Advertising, communication en PR & $1.7 \%$ \\
General services & $1.3 \%$ \\
\end{tabular}


Table 9 (continued)

\begin{tabular}{|c|c|}
\hline Socio-demo variable & Percentage \\
\hline Auditing, accounting & $0.4 \%$ \\
\hline Banking, financial services and insurance & $1.3 \%$ \\
\hline Construction & $0.4 \%$ \\
\hline Chemical and petrochemical industry & $0.4 \%$ \\
\hline Consulting & $11.4 \%$ \\
\hline Distribution, transport and logistics & $0.8 \%$ \\
\hline Pharmaceutical industry & $1.7 \%$ \\
\hline Wholesale, retail & $0.4 \%$ \\
\hline $\mathrm{HR}$, recruitment and selection & $2.1 \%$ \\
\hline ICT & $64.6 \%$ \\
\hline Legal sector & $0.8 \%$ \\
\hline Manufacturing, production & $1.7 \%$ \\
\hline Medical, social and healthcare & $4.2 \%$ \\
\hline Metal industry & $0.8 \%$ \\
\hline Military & $0.4 \%$ \\
\hline Education and training & $1.3 \%$ \\
\hline Public services, government & $0.4 \%$ \\
\hline Sport & $0.4 \%$ \\
\hline University, college & $0.4 \%$ \\
\hline Others & $3.0 \%$ \\
\hline \multicolumn{2}{|l|}{ Function } \\
\hline Academic research & $0.4 \%$ \\
\hline Civil servant: Level 1 & $0.4 \%$ \\
\hline Civil servant: Level 2 & $0.4 \%$ \\
\hline Blue collar & $1.3 \%$ \\
\hline White collar: Administrative and support staff & $22.8 \%$ \\
\hline White collar: Higher management & $3.4 \%$ \\
\hline White collar: Middle management & $11.4 \%$ \\
\hline $\begin{array}{l}\text { White collar: Professional/Expert (expert role without } \\
\text { managerial authority) }\end{array}$ & $44.3 \%$ \\
\hline Politics & $0.4 \%$ \\
\hline Freelancer & $1.3 \%$ \\
\hline Independent & $9.7 \%$ \\
\hline Sales & $1.3 \%$ \\
\hline Others & $3.0 \%$ \\
\hline \multicolumn{2}{|l|}{ Regime } \\
\hline Full-time & $92.0 \%$ \\
\hline Part-time & $8.0 \%$ \\
\hline \multicolumn{2}{|l|}{ Tenure } \\
\hline$<1$ year & $28 \%$ \\
\hline $1-5$ years & $47 \%$ \\
\hline $6-10$ years & $15 \%$ \\
\hline $11-20$ years & $8 \%$ \\
\hline $21-30$ years & $2 \%$ \\
\hline
\end{tabular}




\section{Declarations}

All procedures performed in this study were in accordance with the ethical standards of the institutional research committee and with the 1964 Helsinki Declaration and its later amendments or comparable ethical standards.

Informed Consent All participants gave their consent for participation in the study.

Conflict of Interest The authors declare that they have no conflict of interest.

Open Access This article is licensed under a Creative Commons Attribution 4.0 International License, which permits use, sharing, adaptation, distribution and reproduction in any medium or format, as long as you give appropriate credit to the original author(s) and the source, provide a link to the Creative Commons licence, and indicate if changes were made. The images or other third party material in this article are included in the article's Creative Commons licence, unless indicated otherwise in a credit line to the material. If material is not included in the article's Creative Commons licence and your intended use is not permitted by statutory regulation or exceeds the permitted use, you will need to obtain permission directly from the copyright holder. To view a copy of this licence, visit http://creativecommons.org/licenses/by/4.0/.

\section{References}

Bal, P. M., \& Vink, R. (2011). Ideological currency in psychological contracts: The role of team relationships in a reciprocity perspective. International Journal of Human Resource Management, 22(13), 2794-2817. https://doi.org/10.1080/09585192.2011.560869

Bingham, J. B. (2005). Multiple obligations: Distinguishing the dimensionality and confirming the role of ideology within the psychological contract framework. Doctoral Dissertation.

Bono, J. E., \& Judge, T. A. (2003). Core self-evaluations : A review of the trait and its role in job satisfaction and job performance. European Journal of Personality, 17, 5-18.

Bordia, P., Restubog, S. L. D., \& Tang, R. L. (2008). When employees strike Back : Investigating mediating mechanisms between psychological contract breach and workplace deviance. Journal of Applied Psychology, 93(5), 1104-1117. https://doi.org/10.1037/0021-9010.93.5.1104

Cassar, V., \& Briner, R. B. (2011). The relationship between psychological contract breach and organizational commitment: Exchange imbalance as a moderator of the mediating role of violation. Journal of Vocational Behavior, 78(2), 283-289. https://doi.org/10.1016/j.jvb.2010.09.007

Conway, N., \& Briner, R. B. (2002a). Full-time versus part-time employees: Understanding the links between work status, the psychological contract, and attitudes. Journal of Vocational Behavior, 61(2), 279-301. https://doi.org/10.1006/jvbe.2001.1857

Conway, N., \& Briner, R. B. (2002b). A daily diary study of affective responses to psychological contract breach and exceeded promises. Journal of Organizational Behavior, 23(3), 287-302. https://doi.org/ 10.1002/job.139

Conway, N., \& Coyle-Shapiro, J. A. M. (2012). The reciprocal relationship between psychological contract fulfilment and employee performance and the moderating role of perceived organizational support and tenure. Journal of Occupational and Organizational Psychology, 85(2), 277-299. https://doi.org/10. 1111/j.2044-8325.2011.02033.x

Coyle-Shapiro, J. A.-M., Pereira Costa, S., Doden, W., \& Chang, C. (2019). Psychological contracts: Past, present, and future. Annual Review of Organizational Psychology and Organizational Behavior, 6(1), 145-169. https://doi.org/10.1146/annurev-orgpsych-012218-015212

Dahling, J. J., Chau, S. L., Mayer, D. M., \& Gregory, J. B. (2012). Breaking rules for the right reasons ? An investigation of pro-social rule breaking. Journal of Organizational Behavior, 42, 21-42. https://doi. org/10.1002/job

de Jong, J., Rigotti, T., \& Mulder, J. (2017). One after the other: Effects of sequence patterns of breached and overfulfilled obligations. European Journal of Work and Organizational Psychology, 26(3), 337355. https://doi.org/10.1080/1359432X.2017.1287074

Edwards, J. R., \& Parry, M. E. (1993). On the use of polynomial regression equations as an alternative to difference scores in organizational research. Academy of Management Journal, 36(6), 1577-1613. https://doi.org/10.2307/256822 
Etikan, I., Musa, S. A., \& Alkassim, R. S. (2016). Comparison of convenience sampling and purposive sampling. American Journal of Theoretical and Applied Statistics, 5(1), 1. https://doi.org/10.11648/j. ajtas.20160501.11

Griep, Y., \& Vantilborgh, T. (2018). Reciprocal effects of psychological contract breach on counterproductive and organizational citizenship behaviors: The role of time. Journal of Vocational Behavior, 104(April 2017), 141-153. https://doi.org/10.1016/j.jvb.2017.10.013

Gupta, B., Bajwa, S. J. S., Malhotra, N., Mehdiratta, L., \& Kakkar, K. (2020). Tough times and miles to go before we sleep- Corona warriors. Indian Journal of Anaesthesia, 64(4), 257-262. https://doi.org/10. 4103/ija.IJA

Judge, T. A., \& Bono, J. E. (2001). Relationship of Core self-evaluations traits - Self-esteem , generalized self-efficacy, locus of control, and emotional stability - With job satisfaction and job performance : A Meta-analysis. Journal of Applied Psychology, 86(1), 80-92. https://doi.org/10.1037//0021-9010. 86.1.80

Judge, T. A., Locke, E. A., Durham, C. C., \& Kluger, A. N. (1998). Dispositional effects on job and life satisfaction: The role of core evaluations. Journal of Applied Psychology, 83(1), 17-34. https://doi.org/ 10.1037/0021-9010.83.1.17

Judge, T. A., Erez, A., Bono, J., \& Thoresen, C. J. (2003). The core self-evaluations scale: Development of a measure. Personal Psychology, 56, 303-331.

Krause, A. J., \& Moore, S. Y. (2017). Ideological currency in the psychological contracts of corporate manufacturing employees. Employee Responsibilities and Rights Journal, 29(1), 15-36. https://doi.org/10. 1007/s 10672-017-9289-1

Lambert, L. S., Edwards, J. R., \& Cable, D. M. (2003). Breach and fulfillment of the psychological contract: A comparison of traditional and expanded views. Personnel Psychology. https://doi.org/10.1111/j. 1744-6570.2003.tb00244.x

Montes, S. D., \& Zweig, D. (2009). Do promises matter? An exploration of the role of promises in psychological contract breach. Journal of Applied Psychology, 94(5), 1243-1260. https://doi.org/10.1037/ a0015725

Morrison, E. W. (2006). Doing the job well: An investigation of pro-social rule breaking. Journal of Management, 32(1), 5-28. https://doi.org/10.1177/0149206305277790

Podsakoff, P. M., MacKenzie, S. B., Lee, J. Y., \& Podsakoff, N. P. (2003). Common method biases in behavioral research: A critical review of the literature and recommended remedies. Journal of Applied Psychology, 88(5), 879-903. https://doi.org/10.1037/0021-9010.88.5.879

Robinson, S. L., \& Rousseau, D. M. (1994). Violating the psychological contract: Not the exception but the norm. Journal of Organizational Behavior, 15(3), 245-259. https://doi.org/10.1002/job.4030150306

Rousseau, D. M. (1989). Psychological and implied contracts in organizations. Employee Responsibilities and Rights Journal, 2(2), 121-139. https://doi.org/10.1007/BF01384942

Schermelleh-Engel, K., Moosbrugger, H., \& Müller, H. (2003). Evaluating the fit of structural equation models: Tests of significance and descriptive goodness-of-fit measures. MPR-Online, 8(2), 23-74.

Shih, C. T., \& Chuang, C. H. (2013). Individual differences, psychological contract breach, and organizational citizenship behavior: A moderated mediation study. Asia Pacific Journal of Management, 30(1), 191-210. https://doi.org/10.1007/s10490-012-9294-8

Shum, C., Ghosh, A., \& Gatling, A. (2019). Prosocial rule-breaking to help coworker: Nature , causes , and effect on service performance. International Journal of Hospitality Management, 79(June 2018), 100-109. https://doi.org/10.1016/j.ijhm.2019.01.001

Tavakol, M., \& Dennick, R. (2011). Making sense of Cronbach's alpha. International Journal of Medical Education, 2, 53-55. https://doi.org/10.5116/ijme.4dfb.8dfd

Thompson, J., \& Bunderson, J. S. (2003). Violations of principle : Ideological currency in the psychological contract. Academy of Management Review, 28(4), 571-586.

Vantilborgh, T., Bidee, J., Pepermans, R., Willems, J., Huybrechts, G., \& Jegers, M. (2014). Effects of ideological and relational psychological contract breach and fulfilment on volunteers' work effort. European Journal of Work and Organizational Psychology, 23(2), 217-230. https://doi.org/10.1080/13594 32X.2012.740170

Vantilborgh, T., Bidee, J., Pepermans, R., Griep, Y., \& Hofmans, J. (2016). Antecedents of psychological contract breach: The role of job demands, job resources, and affect. PLoS One, 11(5), 1-22. https://doi. org/10.1371/journal.pone.0154696

Vardaman, J. M., Gondo, M. B., \& Allen, D. G. (2014). Ethical climate and pro-social rule breaking in the workplace. Human Resource Management Review, 24(1), 108-118. https://doi.org/10.1016/j.hrmr. 2012.05.001 
Weißmüller, K. S., De Waele, L., \& van Witteloostuijn, A. (2020). Public service motivation and prosocial rule-breaking: An international vignettes study in Belgium, Germany, and the Netherlands. Review of Public Personnel Administration, 1-61. https://doi.org/10.1177/0734371X20973441

Zhao, H., Wayne, S. J., Glibkowski, B. C., \& Bravo, J. (2007). The impact of psychological contract breach on work-related outcomes: A meta-analysis. Personnel Psychology, 60(3), 647-680. https://doi.org/10. 1111/j.1744-6570.2007.00087.x

Publisher's Note Springer Nature remains neutral with regard to jurisdictional claims in published maps and institutional affiliations. 